Perthe's disease is again a difficult subject and there has been much progress recently in the classification of the hip 'at risk'. The classification and grading is well surveyed by the authors and a modern treatment plan is outlined. Fractures of the femoral neck in childhood together with slipped upper femoral epiphysis are extensively covered by Mr Ratliff. He has also beautifully outlined and illustrated miscellaneous hip problems in childhood and the combined authors have produced a classic work which is very welcome and much overdue. The book is highly recommended.

\section{The Nails in Disease}

By Peter D. Samman. Third Edition. Pp. 197, illustrated. William Heinemann Medical Books, London, 1978 $£ 10.00$.

Already a classic, this elegant treatise has no peer. This third edition enjoys a similar format to the others, but it is just that little bit plumper, stuffed more fully with up-to-date succinct information, and has a greater profusion of pictures.

One must guess that for most of the profession, their knowledge of nails and nail diseases could be tucked into a fairly small mental pigeon hole and their views concerning the significance of disorder of these unobtrusive organs would range from zero to an unprintable comment. Appendix II, thus, might come as a surprise wherein is listed that out of 1100 patients barely 350 suffered from either superficial fungal infections or psoriasis. What of the rest, therefore? Likewise appendix I, the Glossary, will come as a distinct shock to medical men and classicists alike - what can 'agnail' and 'onychoheterotropia' mean? - enough to give anyone onychalgia nervosa and drive him into a frenzy of onychotillomania.

The first chapter of the total of 12, Anatomy and Physiology, fully but laconically, with the aid of excellent line drawings, photomicrographs and radiographs explains the fundamentals so that chapter 2, Principal Nail Symptoms, also admirably explicit, is entirely intelligible and they both, in a mere 25 pages, serve as a marvellous introduction to disease.

Psoriasis takes pride of place, and then fungus infection but, despite the 33 illustrations which these chapters share, and the simple and unambiguous text, doctors will continue to muddle their diagnoses and prescribe the costly fungal antibiotic griseofulvin inappropriately for these conditions and for the nail dystrophy associated with chronic paronychia, the subject of the next chapter. Then a chapter that deals with the 2 other very common red, scaly, dermatoses, dermatitis and lichen planus, and the nail changes of alopecia areata and some dermatological oddities. Acquired Nail Disorders is the next chapter, and these range from infective, pustular but non-infective, dramatic but unimportant, and various. General physicians will be interested in chapters 8 , Impaired Peripheral Circulation, and 9, General Medical Conditions, and will be able to find out what Terry actually did describe, when Beau named his lines, and why the yellow nail syndrome, described by the author in 1964, is of importance to the patient's system.

Chapter 10, Trauma, the causes ranging from nail varnish, nail biting, nail picking, and nail bashing by footwear, accounts for a large proportion of the nail dystrophies that bring the patient to the doctor. Tumours, Chapter 11, benign ones notably warts, and curious ones such as subungual exostoses, Developmental Abnormalities, Chapter 12, and some of these one would scarcely credit as genuine and, like the giraffe had one not seen an example one would not believe it, completes a volume which every dermatologist who is not blessed with an earlier edition, must own and every medical library must buy.
Occurrence, Diagnosis and Sources of Hospital-Associated Infections (Handbook on Hospital-Associated Infections, Vol. 1)

Edited by W. J. Fahlberg and D. Gröschel. Pp. 138, hard cover illustrated. Marcel Dekker Inc., New York and $\stackrel{5}{\rightarrow}$ Basel, 1978. Sw. fr. 45.00.

This book offers a useful general framework for its important subject, its fundamental defect is that it 'is aimed at the broadest spectrum of health care personnel ... including individuals in central services, housekeeping, dietary, and laundry'. This is of course an impossible target. It could have been reached only in the non-technical opening section on the historical background; but this is too brief and stops, unaccountably, in the 1880s. Experienced teachers of this subject know that their students can only achieve adequate perspective by appreciating the fascinating evolutionary changes that have occurred continuously right up to the present day in hospitals, patients, and micro-organisms alike.

In its 4 main sections the book concisely reviews the clinical, laboratory, therapeutic and aetiological aspects of hospital infection. Here the reader is constantly aware of an uneasy balance between the technical discussion that is required by a medical audience and the simpler approach sought by other groups. Junior clinical students would undoubtedly obtain from this book a helpful impression of the many complex problems now posed by infections in our hospitals. Unfortunately, however, the audience who could gain most from the book is the least likely to be able to afford it. Although cheaply printed, the slim volume is highly priced in Swiss francs. Its cost in terms of weaker currencies is at least twice as much as for equivalent indigenous books.

Physiology of the Eye. An Introduction to the Vegetative Functions

By Irving Fatr. Pp. viii +232 , illustrated. Butterworths Boston and London, 1978. £13.00 U.S. \$26.00.

The curious subtitle An Introduction to the Vegetative Functions seems inapt on the basis of the definition of vegetative as 'to live like a vegetable or to live an inactive almost purely physical, or dull life'. Professor Irving Fatt writes on the physiology of the eye in a manner which makes the subject seem anything but a dull life. Here is a book which fills a most useful gap in the literature of physiology. In the preface the author correctly comments that he could not find an introductory textbook to the physiology of the eye and has based his book on lecture notes given at the University of California in Berkeley. By vegetative physiology he means the biophysical and biochemical processes that maintain the eye in its normal state.

The book is divided into successive chapters on Anatomy, The Aqueous Humor, The Intra-ocular Pressure, The Vitreous Body, The Lens, The Cornea, The Sclera, The Retina and The Tears and Lids. This arrangement deliberately corresponds to the arrangement in Davson's The Ej'e so that readers may use the two books to complement each other (also a deserved compliment to Hugh Davson's book). The Aqueous and the Cornea alone form more than half the 222 pages of the book which reflects the knowledge of physiology in these subjects. There is much excellent and concise information in these chapters and there are in particular many justified references to $D$. M. Maurice's work on corneal physiology. The illustrations, all in black and white, are well drawn and liberally used. In particular the measurement and physiology of intra-ocular pressure are dealt with in detail which reflects the usefulness of this book to optometric students. The chapters on the Vitreous and the Lens are somewhat sparse which is a disappointment as there has been much useful work on these topics in recent years which could have been included. The Sclera warrants \title{
.
}


4 pages only and the Retina 10 pages but both are models of succinct writing. The final chapter on The Tears and the Lids is especially useful with some new information on the eyelid during blinking.

Professor Fatt indicates in his preface that he has deliberately omitted the electrophysiology of the optic nerve, retina and extra-ocular muscles. This is understandable in the interests of brevity but probably the book could achieve a much wider readership if these were included in any future editions. A most excellent and readable little book which will be obligatory reading for optometric students, those embarking on ocular physiology research and any member of one of the health professions requiring a good introduction to the physiology of the eye.

\section{Recent Advances in Gastroenterology}

Edited by Ian A. D. Bouchier. Pp. viii +338 , hard cover, illustrated. Churchill Livingstone, Edinburgh, 1976.

This is number 3 in the ever popular Recent Advances in Gastroenterology series, with chapters by 18 authors, 9 from the U.K., 3 Canadians and 6 from the U.S.A. Progress in gastroenterology has been so rapid that the editor, Professor Bouchier faces a self-confessed unenviably difficult choice. Quite rightly, paediatric gastroenterology claims 2 chapters on liver disease in infants and children and on cystic fibrosis of the pancreas. The use and abuse of laxatives is dealt with authoritatively, references dated up to 1975 documenting continuing developments in this area. Hormonesecreting tumours of the gut, effects of small bowel resection, and of alcohol on the gut, endoscopic cannulation of the papilla of Vater, bile acid metabolism and shunts for hepatic disease are among the other topics covered. There are good reviews of fat absorption. The chapter on hiatus hernia and the gastro-oesophageal junction is disappointing, not because the review of the literature is incomplete, but because of absence of any critical evaluation of the various studies cited and of their relevance to clinical practice. Review of the connective tissue disorders that affect the gut provides a link with general medicine and a useful reminder of some of the rarer diagnoses. The book is produced and illustrated to a high standard. It is to be highly recommended, both for libraries and for personal bookshelves of general physicians and gastroenterologists. The Editor can be congratulated on an expert job of work and on his iconoclastic omissions of the sacred cows of fibre, therapy of peptic ulcer and medical treatment of gall stones.

Sexual Endocrinology. Hormone Relations and the Physiopathology of Pregnancy. Hormone Investigations. Hypothalamic-Hypophyseal Relations

Edited by R. Vokaer and R. De Mauberge. Pp. viii +272 , illustrated. Masson Publishing: New York, Paris, Barcelona and Milan. Abacus Press, Tunbridge Wells, 1978. $£ 26.35$.

Most people agree that too many medical and para-medical books are published. Sexual Endocrinology edited by Vokaer and Mauberge is one of the too many. It consists of 17 chapters on a variety of subjects in the general field of reproductive endocrinology. They vary from $1 \frac{1}{2}$ to 30 pages in length and mainly contain information that has been published elsewhere, not only in the form of original scientific articles but also within widely available reviews, often by the same authors. The book costs $£ 26.35$. I do not recommend you to buy it.

\section{Soft Contact Lenses. Clinical and Applied Technology}

Edited by Montague Ruben. Pp. xiii +496 , illustrated. Baillière Tindall, London, 1978. £21.00.

The size of this book, almost 500 pages, is an indication of the enormous interest and advances made specifically in soft contact lenses since their introduction into clinical practice during 1961. Montague Ruben, an expert in the field of contact lenses in general, is the editor of this beautifully produced book. There are 28 contributors each one concentrating on an aspect of the soft contact lens with which he has particular experience. The editor rightly states this is not a book for the beginner but even those with a rudimentary knowledge of soft contact lenses would find the book fascinating reading. For the expert in the clinical use of soft lenses there is much to be gained from the sections dealing with technology and applied science. For the researcher there is much to be learned from the clinical practical sections.

The book has 5 sections, each one dealing with a special aspect of the soft contact lens, commencing with the Historical Development and continuing through Applied Sciences, Clinical Practice, Pathology, Toxicology and Pharmacology, and finally the Technology of Manufacture. The editor himself contributes to the sections on Clinical Practice and Pathology. An international flavour to the book is apparent, not only from the styles of writing but from the fact that 10 different countries are represented amongst the 28 contributors. Printed in clear type on quality paper there are liberal, beautifully reproduced illustrations. The size, definition and quality of most of the tables and diagrams is a model for others to follow. There is a centre insert of 18 pages of excellent colour photographs relating to different sections in the book. As always, it is a minor irritation not having these colour illustrations with the text but the increase in cost involved presumably gives rise to this arrangement.

The editor and contributors are to be congratulated on a first class book which will remain essential reading for all those involved in the clinical practice of soft contact lenses for years to come. A comprehensive book of this nature has been much needed. Researchers will find much basic and advanced information not easily obtained in such a readable form with copious references. At $£ 21.00$ this book may seem a little expensive but for the content and quality it must be considered good value, and is highly recommended.

\section{The Wheelchair Child}

By Philippa Russell. Human Horizons Series. Pp. 388 , illustrated. Souvenir Press Ltd, London, 1978. £6.00.

This is an important book for physiotherapists, occupational therapists, doctors and surgeons dealing with the handicapped child.

There are many interesting thoughts on mobility aids for the disabled, and these also include other related walking frames, chariots and similar appliances. Physiotherapy, play therapy and other treatments of the disabled person using this apparatus are also well covered.

At the modest price of $£ 6$ it is highly recommended for all those dealing with the handicapped child. 